\title{
Quantification of Viable Bioaerosol Emanation from an ACMV System and its Impact on Indoor Bioaerosol Pollution
}

\author{
Jin Wen Xiong ${ }^{1}$, Man Pun Wan ${ }^{2 *}$, Bing Feng $\mathrm{Ng}^{2}$, Siming You ${ }^{3}$ \\ ${ }^{1}$ Energy Research Institute @ NTU, Nanyang Technological University, Singapore 637553, Singapore \\ ${ }^{2}$ School of Mechanical and Aerospace Engineering, Nanyang Technological University, Singapore 639798, Singapore \\ ${ }^{3}$ School of Engineering, University of Glasgow, Glasgow G12 8QQ, Scotland
}

\begin{abstract}
Viable bioaerosol can deposit and multiply in air-conditioning and mechanical ventilation (ACMV) systems, eventually entering indoor environments after these systems are operated and contributing to indoor pollution. We propose a method for identifying and quantifying the emanation of viable bioaerosol from an ACMV system and its impact on indoor pollution through surface and air sampling followed by analysis using a material-balance model. Adopting this method, we investigated the contribution of viable bioaerosol from an ACMV system to the indoor pollution in an air-conditioned room located in Singapore. The system, which emanated viable bacteria and viable fungi at the rates of $2.4 \mathrm{CFU} \mathrm{s}^{-1}$ and $3.9 \mathrm{CFU} \mathrm{s}^{-1}$, respectively, was the largest source of indoor viable bacteria and the second largest source of indoor viable fungi (exceeded only by the outdoor fungi introduced through mechanical ventilation) in the air. Potentially pathogenic bioaerosol species in the genera of Staphylococcus, Moraxella and Aspergillus were also identified in the ACMV system. In particular, Moraxella osloensis, the most likely genus to originate from occupants, was found to accumulate in the ACMV system, indicating the potential effect of this system's cleanliness on indoor pollution. Our method can be used as a tool for analysing the potential sources of indoor bioaerosol and supporting the development of effective control measures for bioaerosol emanation from ACMV systems.
\end{abstract}

Keywords: Indoor bioaerosol dynamics; Natural ventilation; Bacteria; Fungi.

\section{NOMENCLATURE}

A Floor area $\left(\mathrm{m}^{2}\right)$

C Bioaerosol concentration $\left(\mathrm{CFU} \mathrm{m} \mathrm{m}^{-3}\right)$

$C_{\mathrm{i}} \quad$ Indoor bioaerosol concentration $\left(\mathrm{CFU} \mathrm{m} \mathrm{m}^{-3}\right)$

$C_{\mathrm{i}, 1} \quad$ Contribution of initial bioaerosol concentration $\left(\mathrm{CFU} \mathrm{m} \mathrm{m}^{-3}\right.$ )

$C_{\mathrm{i}, 2} \quad$ Contribution of bioaerosol resuspension from the floor $\left(\mathrm{CFU} \mathrm{m} \mathrm{m}^{-3}\right)$

$C_{\mathrm{i}, 3} \quad$ Contribution of the potential bioaerosol emanation sources including occupants, the fresh air duct and the $\mathrm{AC}$ unit and the introduction of outdoor bioaerosols through the mechanical ventilation $\left(\mathrm{CFU} \mathrm{\textrm {m } ^ { - 3 }}\right)$

$E_{0} \quad$ The rate of supply of bioaerosols from outdoors through mechanical ventilation $\left(\mathrm{CFU} \mathrm{s}^{-1}\right)$

$E_{1} \quad$ Bioaerosol emanation rate of occupants $\left(\mathrm{CFU} \mathrm{s}^{-1}\right)$

\footnotetext{
* Corresponding author.

Tel.: (+65) 67906957; Fax: (+65) 67906957

E-mail address: mpwan@ntu.edu.sg
}

$E_{2} \quad$ Bioaerosol emanation rate of the $\mathrm{AC}$ unit $\left(\mathrm{CFU} \mathrm{s}^{-1}\right.$ )

$E_{3} \quad$ Bioaerosol emanation rate of the fresh air duct (CFU s ${ }^{-1}$ )

F Sampling air flow rate of the impactor (14.15 $\mathrm{L} \mathrm{min}^{-1}$ )

$N \quad$ Bacterial or fungal loadings on surfaces (CFU m ${ }^{-2}$ )

$N_{\text {floor }} \quad$ Bacterial and fungal loadings on the floor (CFU m ${ }^{-2}$ )

$n \quad$ Number of colonies on an agar plate (CFU)

$R_{\text {floor }} \quad$ Resuspension rate of bacteria and fungi from the floor $\left(\# \mathrm{~s}^{-1}\right)$

$r \quad$ Ratio of the volume $(100 \mu \mathrm{L})$ of liquid sample spread on an agar plate to the volume $(10 \mathrm{~mL})$ of eluted ultra-pure water from one swab

$S_{\mathrm{t}} \quad$ Template area of surface sampling $\left(0.005 \mathrm{~m}^{2}\right)$

$t \quad$ Time (s)

$t_{\mathrm{s}} \quad$ Sampling time for each air sample $(10 \mathrm{~min})$

$Q_{\mathrm{f}} \quad$ Fresh air flow rate $\left(\mathrm{m}^{3} \mathrm{~s}^{-1}\right)$

$Q_{\mathrm{r}} \quad$ Return air flow rate $\left(\mathrm{m}^{3} \mathrm{~s}^{-1}\right)$

$V \quad$ Volume of indoor space $\left(\mathrm{m}^{3}\right)$

$V_{\mathrm{d}} \quad$ Deposition velocity of indoor bioaerosols on the floor $\left(\mathrm{m} \mathrm{s}^{-1}\right)$ 
$\eta_{1} \quad$ Filtration efficiency of the return air filter inside the $\mathrm{AC}$ unit

\section{INTRODUCTION}

Air-conditioning and mechanical ventilation (ACMV) systems are widely used to provide a comfortable indoor environment (Cheong and Lau, 2003), especially in the tropical region where air-conditioning is needed all year round (Aziz et al., 2017). In Singapore, ACMV systems are widely adopted in buildings (Chen and Chang, 2012). In many cases, an ACMV system also serves as an engineering means to control indoor air quality (Zhao and $\mathrm{Wu}, 2009$; Chen et al., 2016). However, whether an ACMV system is helping to control indoor air quality or is worsening indoor air quality remains debatable. An increasing number of studies have shown that ACMV systems can also serve as sources of indoor aerosols (Batterman and Burge, 1995; Bluyssen et al., 2003). Studies indicated that cooling coils of an ACMV system could be a potential aerosol source via air-flow-induced particle resuspension from the surfaces of the cooling coils when they were contaminated by particulate matter (Siegel and Carey, 2001; Siegel, 2002). Zhou et al. (2011) also found that particle resuspension from highly contaminated air ducts led to as much indoor aerosol pollution as that caused by indoor human activities, such as cleaning and playing for 60 minutes.

Bioaerosol, especially airborne bacteria and fungi, is an important concern for indoor environments (Lal et al., 2017). Human exposure to airborne bacteria and fungi can lead to serious infectious diseases (Cole and Cook, 1998; Daniels et al., 2016; Fan et al., 2017; Kim et al., 2017) such as Legionnaires' disease (Berrington and Hawn, 2013), tuberculosis (TB) (Pedersen et al., 2016) and pneumonic plague (Hammamieh et al., 2016). In addition, some allergens such as spores and hyphae (Jutel et al., 2016), which can cause serious respiratory diseases (Hargreaves et al., 2003; Vesper et al., 2008; Beck et al., 2012; Du et al., 2018), are found in indoor bioaerosols. Indoor bioaerosols consist of viable and non-viable portions (Nazaroff, 2016). Although non-viable bioaerosols can cause allergies when occupants are exposed to them (Kauffman and van der Heide, 2003), they do not multiply in the environment. The viable bioaerosols can deposit, accumulate and subsequently multiply on the surfaces of various components of an ACMV system under favourable conditions, exacerbating the biological contamination of the ACMV system (Batterman and Burge, 1995; Siegel and Carey, 2001; Zhao and Wu, 2006; Lu et al., 2009; Bonetta et al., 2010; Chen and Chang, 2012; Schmidt et al., 2012; Wu et al., 2016). These findings indicate the potential of ACMV systems to be bioaerosol emanation sources. Jo and Lee (2008) observed that switching on an ACMV system could lead to an instantaneous increase in concentrations of indoor airborne viable bacteria and fungi. However, little study has been conducted to quantify the bioaerosol emanation rate from ACMV systems and identify the species of bioaerosols emanated from ACMV systems.

This work experimentally investigates the emanation of viable bacteria and fungi from an ACMV system and its contribution to indoor bioaerosol pollution in a tropical indoor environment, where the environmental conditions are generally favourable to growth of microorganisms (Chen and Chang, 2012). Both air and surface sampling methods are employed for viable bioaerosol quantification and species identification. The result of this study could contribute to the understanding of bioaerosol emanation from ACMV systems and their impact on indoor bioaerosol pollution.

\section{METHODOLOGY}

\section{Experimental Site}

Experiments were conducted in a tutorial room $(6.30 \mathrm{~m}[\mathrm{~L}]$ $\times 5.80 \mathrm{~m}[\mathrm{~W}] \times 2.80 \mathrm{~m}[\mathrm{H}])$ located at Nanyang Technological University (NTU), Singapore. A schematic diagram of the tutorial room is shown in Fig. 1. The ACMV system of the room consists of a ceiling-mounted cassette-type airconditioning (AC) unit (plfy-p63vam-e; Mitsubishi Electric) and a fresh air duct. The AC unit draws room return air through a grill that has a Minimum Efficiency Reporting Value (MERV)-4 rating return air filter installed, which provides a minimum filtration efficiency of less than $20 \%$ for particles of diameters from 0.3 to $10.0 \mu \mathrm{m}$ according to ASHRAE Standard 52.2 (ASHRAE, 2017). The AC unit also draws outdoor air via a 22.8-m-long fresh air duct. A fresh air filter of MERV-8 rating (minimum filtration efficiency of less than $10 \%$ for particles of diameters from 0.3 to $1.0 \mu \mathrm{m}$, and that of less than $70 \%$ for particles of diameters from 1.0 to $3.0 \mu \mathrm{m}$, and that of $70-85 \%$ for particles of diameters from 3.0 to $10.0 \mu \mathrm{m}$ according to ASHRAE Standard 52.2; ASHRAE, 2017) is installed at about $3.2 \mathrm{~m}$ downstream of the fresh air intake. The supply air flow rate of the AC unit is $1400 \mathrm{~m}^{3} \mathrm{~h}^{-1}$, a constant air volume. When the tutorial room is operated in ACMV mode, the indoor air temperature set point is $24^{\circ} \mathrm{C}$ and relative humidity ( $\mathrm{RH}$ ) set point is $60 \%$, which is set according to the recommendation from Singapore Standard 554 (SSC, 2016). The tutorial room can also be operated in natural ventilation mode. There is a sliding window $\left(2.5 \mathrm{~m}^{2}\right)$ on the wall. When the room is naturally ventilated, the window is open, and the AC unit is switched off.

\section{Air Sampling of Bioaerosols}

In this study, culture-based air sampling method was used to measure concentrations of indoor viable bacteria and fungi in the air. The culture-based air sampling method is widely adopted for measuring indoor bioaerosol concentrations, e.g., Singapore Standard SS554 (Iyengar, 2014), WHO indoor air quality guideline (Heseltine and Rosen, 2009), Occupational Safety and Health Administration (OSHA) (Kim et al., 2017), the Health and Welfare Department in Canada (Kim et al., 2017) and Indoor Air Quality Association (Kim et al., 2017). Many studies employed culture-based air sampling method to quantify bacterial and fungal concentrations for validating predictions of indoor bioaerosol concentrations by mathematical formulas (Scheff et al., 2000; Green et al., 2003; Hathway et al., 2011; King et al., 2013).

Air sampling was conducted using a 200-hole, one-stage impactor (SKC) loaded with a petri dish with culture medium. A sampling flow rate of $14.15 \mathrm{~L} \mathrm{~min}^{-1}$ was provided by a sampling pump. The median cut-point $\left(\mathrm{D}_{50}\right)$ of the 


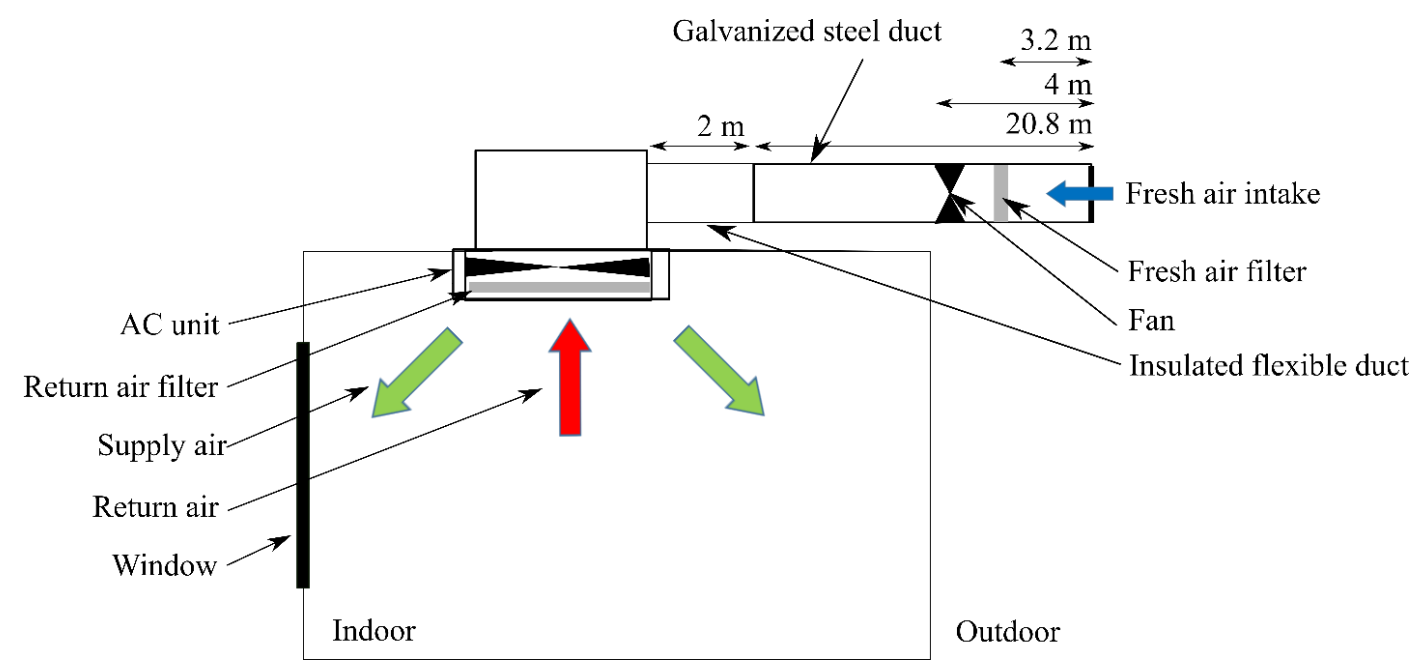

Fig. 1. Schematic diagram of the experimental tutorial room.

impactor at the sampling flow rate is $0.6 \mu \mathrm{m}$. Tryptic soy agar with addition of cycloheximide was used as the culture medium for bacteria. Malt extract agar with addition of chloramphenicol was used as the culture medium for fungi. Sampled bacterial agar plates were incubated for 48 hours in $35^{\circ} \mathrm{C}$ whereas fungal agar plates were incubated for 72 hours in $27^{\circ} \mathrm{C}$, before colony counting. The colony counts were subsequently corrected using the method suggested by Macher (1989). The bacterial and fungal concentration $(C$; colony forming unit [CFU] per cubic meters) is calculated as $C=$ $1000 n /\left(F \cdot t_{\mathrm{s}}\right)$, where $n(\mathrm{CFU})$ is the corrected number of colonies on a sampled agar plate. $F=14.15 \mathrm{~L} \mathrm{~min}^{-1}$ is the sampling air flow rate of the impactor with an agar plate inside. $t_{\mathrm{s}}=10 \mathrm{~min}$ is the sampling time for each sample. Measurement uncertainty of indoor bacterial and fungal concentrations using the impactor is $7.67 \mathrm{CFU} \mathrm{m}^{-3}$. Preparation of agar plates, and incubation and colony counting of air-sampled agar plates are described in Supplemental Material. We understand that CFU is not a direct reflection of bioaerosol amount. However, due to the fact that the culture-based air sampling method was used in this study, $\mathrm{CFU} \mathrm{m}^{-3}$ is the representation unit of bioaerosol concentrations with this method.

Air sampling of indoor viable bacteria and fungi was conducted from 9:25 AM to 4:35 PM in a day. There was a 20-minute interval between two successive air samplings. Therefore, 15 pairs of air samples (15 air samples for bacterial cultivation and 15 air samples for fungal cultivation) could be collected in a day.

\section{Surface Sampling of Indoor Surfaces}

Surface sampling was conducted to quantify loadings of viable bacteria and fungi on indoor surfaces. Surface sampling was performed using SKC surface swab kits. A swab kit includes a sterile foam swab and a $5 \mathrm{~cm} \times 10 \mathrm{~cm}$ plastic template that defines the target sampling area. During a surface sampling, the target area defined by the template was swabbed thoroughly in a rolling mode using the sterile foam swab. After sampling, the foam swab was kept in the sterile storage tube that came with the kit and was then transported back to the laboratory for culture-based analysis.
To extract the surface sample from the swab kit, $10 \mathrm{~mL}$ of ultra-pure water was added to each storage tube containing the sampled swab. The tubes were then vortex-shaken in a vortex mixer (SPD Scientific) for one minute. The liquid sample eluted from the swab was then transferred to a clean tube. Next, $100 \mu \mathrm{L}$ of the liquid sample was extracted by a pipette (Hirschmann) and distributed on an agar plate for cultivation. Five repeats of agar plates were made for each eluted liquid sample. Incubation and colony counting of surface samples shares the same method as that for air sampling. Bacterial and fungal loadings on the sampled surface $(N)$ can be calculated as $N=n /\left(r \cdot S_{\mathrm{t}}\right)$, where $n$ is the number of colonies on an agar plate. $r=0.01$ is the ratio of volume of extracted liquid sample $(100 \mu \mathrm{L})$ that distributed on an agar plate to the volume $(10 \mathrm{~mL})$ of eluted ultra-pure water from one swab (volume of liquid sample in the storage tube after adding $10 \mathrm{~mL}$ ultra-pure water) and $S_{t}=0.005 \mathrm{~m}^{2}$ is the area that the plastic template defines for surface sampling.

\section{Experiment Design \\ Indoor Bioaerosol Model}

Damped areas such as rotted food or damaged furniture were not found in the tutorial room. Before the experiments, air leakages of the room, such as door gaps, were sealed by tapes to minimize the penetration of outdoor bioaerosols to the indoor space through the leakages. Contribution of the penetration of outdoor bioaerosols through the leakages to indoor bioaerosol concentration was assumed to be negligible. As such, introduction of outdoor bioaerosols through the mechanical ventilation, and bioaerosols emanated from occupants and the ACMV system, as well as bioaerosol resuspension from the floor were the bioaerosol sources indoors when the room was operated in the ACMV mode. When the room was operated in the ACMV mode, two assumptions were made for the indoor bioaerosol dynamics in this study: 1) In the experiment, indoor bioaerosols were assumed to be well mixed in the tutorial room. In a previous study, indoor aerosols were assumed to be well mixed in an indoor space of a dimension of $5 \mathrm{~m}(\mathrm{~L}) \times 6 \mathrm{~m}(\mathrm{~W}) \times 3 \mathrm{~m}(\mathrm{H})$ 
when the air mixing rate was $6 \mathrm{~h}^{-1}$ and duration of air mixing was 8 hours in the indoor space (Zhou et al., 2011). In this study, dimensions of the tutorial room $(6.30 \mathrm{~m}[\mathrm{~L}] \times$ $5.80 \mathrm{~m}[\mathrm{~W}] \times 2.80 \mathrm{~m}[\mathrm{H}])$ and duration of air mixing in the experiment ( 7 hours) were similar to those in the previous study (Zhou et al., 2011). Meanwhile, the air mixing rate of the tutorial room in the ACMV mode was $13.7 \mathrm{~h}^{-1}$ in this experiment, which was more than double of that of the indoor space in the previous study (Zhou et al., 2011). Therefore, indoor bioaerosols, as a subset of aerosols, could be assumed to be well mixed in the experiment in this study. 2) Coagulation could be assumed to be negligible due to low concentrations of indoor bioaerosols (less than $10^{5}$ to $10^{8} \mathrm{~m}^{-3}$ ) (Zhou et al., 2011), which can be found in the measurement results of indoor bioaerosol concentrations in the next section. Then the material-balance equation of indoor bioaerosols when the room was operated in the ACMV mode can be given by:

$$
V \frac{d C_{i}}{d t}=-C_{i} Q_{f}-Q_{r} \eta_{1} C_{i}+R_{\text {floor }} N_{\text {floor }} A-V_{d} C_{i} A+\sum_{j=0}^{3} E_{j}
$$

The term on the left-hand side of Eq. (1) is the time variation of amount of indoor bioaerosols in the room. On the right-hand side of Eq. (1), $C_{\mathrm{i}} Q_{\mathrm{f}}$ is the rate of indoor bioaerosol exfiltration. $Q_{\mathrm{r}} \eta_{1} C_{\mathrm{i}}$ is the bioaerosol removal rate by the return air filter. $R_{\text {floor }} N_{\text {floor }} A$ is the resuspension rate of bioaerosols from the floor. $V_{\mathrm{d}} C_{\mathrm{i}} A$ is the bioaerosol deposition rate on the floor. $\sum_{j=0}^{3} E_{j}$ is the summation of emission rates from various bioaerosol sources. The solution to Eq. (1) has the following form:

$$
C_{i}(t)=C_{i, 1}(t)+C_{i, 2}(t)+C_{i, 3}(t),
$$

where $C_{\mathrm{i}, 1}$ indicates contribution of initial indoor bioaerosol concentration; $C_{\mathrm{i}, 2}$ denotes contribution of bioaerosol resuspension from the floor; $C_{\mathrm{i}, 3}$ is contribution of bioaerosol emanation sources including occupants, the fresh air duct, the AC unit and introduction of bioaerosols from outdoors through the mechanical ventilation. These items can be fully expressed as:

$$
\begin{aligned}
& C_{i, 1}(t)=C_{i}(0) e-\frac{Q_{f}+Q_{r} \eta_{1}+V_{d} A}{V} t, \\
& C_{i, 2}(t)=\frac{R_{\text {floor }} N_{\text {floor }} A}{Q_{f}+Q_{r} \eta_{1}+V_{d} A}\left(1-e^{-\frac{Q_{f}+Q_{r} \eta_{1}+V_{d} A}{V} t}\right), \\
& C_{i, 3}(t)=\frac{\sum_{j=0}^{3} E_{j}}{Q_{f}+Q_{r} \eta_{1}+V_{d} A}\left(1-e^{-\frac{Q_{f}+Q_{r} \eta_{1}+V_{d} A}{V} t}\right) .
\end{aligned}
$$

The initial condition used to solve Eq. (1) is $C_{\mathrm{i}}=C_{\mathrm{i}}(0)$ at $t=0$, where $C_{\mathrm{i}}(0)$ is the indoor bioaerosol concentration measured at the beginning of the experiment.
A non-linear least squares method was applied to estimate the bacterial and fungal emanation rates by using the mathematical formula expressed by Eq. (2) to fit experimental results of indoor bacterial and fungal concentration. In the above equations, $C_{\mathrm{i}}$ is the indoor bioaerosol concentration. $E_{0}$ is the rate of supply of bioaerosols from outdoors through the mechanical ventilation, $E_{1}$ is the bioaerosol emanation rate of human occupants, $E_{2}$ is the bioaerosol emanation rate of the $\mathrm{AC}$ unit, and $E_{3}$ is the bioaerosol emanation rate of the fresh air duct. The fresh air flow rate $Q_{\text {f }}$ can be calculated according to measurement results of air exchange rates (AERs) and the volume of the tutorial room $(V)$. The return air flow rate $Q_{\mathrm{r}}$ was measured to be $0.37 \mathrm{~m}^{3} \mathrm{~s}^{-1}$. In the indoor environment of the room, the resuspension rate, the filtration efficiency of the MERV 4-rating return air filter and the deposition velocity of indoor bioaerosols can be estimated according to aerodynamic diameters of the indoor bioaerosols (Thatcher and Layton, 1995; Lai, 2002; Zhou et al., 2011). In this study, targeted indoor bioaerosols are indoor viable bacteria and fungi in the air, which are the viable portion of indoor airborne bacteria and fungi. Typical ranges of aerodynamic diameters of the indoor airborne bacteria and fungi are from 0.5 to $2.5 \mu \mathrm{m}$ (Wiedinmyer et al., 2004, 2009) and from 2 to $4 \mu \mathrm{m}$ (Madsen et al., 2016), respectively. Due to the fact that the typical range of aerodynamic diameters of the indoor airborne bacteria and fungi are larger than $0.5 \mu \mathrm{m}$, their deposition are mostly attributed to gravitational settling on upward-facing horizontal surfaces (Whyte and Derks, 2015). Therefore, their deposition on and resuspension from sidewalls and the ceiling of the room can be neglected, and thus the deposition velocity on the floor $V_{\mathrm{d}}$ and the resuspension rate from the floor $R_{\mathrm{floor}}$ are used in Eq. (1). In the experiment, both $V_{\mathrm{d}}$ and $R_{\text {floor }}$ were assumed to be constant with time due to the constant supply air flow rate and a constant indoor activity (sitting) in the tutorial room (Thatcher and Layton, 1995; Zhou et al., 2011). In the material-balance equation, $R_{\text {floor }}, V_{\mathrm{d}}$ and the filtration efficiency of the return air filter $\eta_{1}$ are estimated according to the aerodynamic diameters of the indoor bacteria and fungi and summarised in Table 1.

As shown in Table 1, both the resuspension rate $R_{\text {floor }}$ and the deposition velocity $V_{\mathrm{d}}$ are much less than one, indicating their insignificant impact on the indoor bacterial and fungal concentrations in the period of air sampling. According to the measurement results of filtration efficiency of a MERV 4-rating filter in a previous study (Burroughs, 2005), which has the same filter rating as the return air filter installed in the ACMV system of the tutorial room, both the variation of filtration efficiency of particles within the size range of 0.5$2.5 \mu \mathrm{m}$ and that within the size range of $2-4 \mu \mathrm{m}$ are insignificant, as shown in Table 1. Therefore, the average resuspension rate $R_{\text {floor }}$, the deposition velocity of indoor bioaerosols $V_{\mathrm{d}}$ and the filtration efficiency of the return air filter $\eta_{1}$ in Table 1 were used in Eq. (1). They were calculated for the indoor airborne bacteria and fungi respectively. $A$ is the indoor floor area $(6.30 \mathrm{~m}[\mathrm{~L}] \times 5.80 \mathrm{~m} \mathrm{[W]})$. Bacterial or fungal loadings on the indoor floor surface $N_{\text {floor }}$ were measured by surface sampling using the method described in previous subsection. 
Table 1. Specific parameters used in indoor bioaerosol model.

\begin{tabular}{|c|c|c|c|c|c|}
\hline & \multicolumn{2}{|c|}{ Bacteria } & \multicolumn{2}{|c|}{ Fungi } & \multirow{2}{*}{ Reference } \\
\hline & $0.5-1 \mu \mathrm{m}$ & $1-2.5 \mu \mathrm{m}$ & $2-3 \mu \mathrm{m}$ & $3-4 \mu \mathrm{m}$ & \\
\hline Indoor resuspension rate $\left(R_{\text {floor }}, 10^{-10} \mathrm{~s}^{-1}\right)$ & 1.22 & 50 & 50 & 50 & Zhou et al.(2011) \\
\hline Indoor deposition velocity* $\left(V_{\mathrm{d}}, 10^{-5} \mathrm{~m} \mathrm{~s}^{-1}\right)$ & 1.67 & 9.72 & 9.72 & 36.1 & Zhou et al. (2011) \\
\hline Filtration efficiency of the return air filter* $\left(\eta_{1}\right)$ & 0.04 & 0.09 & 0.12 & 0.12 & Burroughs (2005) \\
\hline
\end{tabular}

${ }^{a}$ Applicable range of aerodynamic diameter $(\mu \mathrm{m})$ : bacteria: $0.5-2.5 \mu \mathrm{m}$ (Wiedinmyer et al., 2004; Wiedinmyer et al., 2009); fungi: 2-4 $\mu \mathrm{m}$ (Madsen et al., 2016).

\section{Experimental Scenarios}

In Eq. (1), $E_{\mathrm{j}}(j=0,1,2,3)$ are unknowns. Four experimental scenarios (Scenario 1-4, as shown in Fig. 2) were designed to determine these unknowns. In each scenario, air sampling of indoor viable bacteria and fungi repeated for five successive weekdays. Therefore, 75 pairs of air samples were collected for each scenario. Subsequently, a non-linear least squares method was applied to estimate the bacterial and fungal emanation rates, $E_{\mathrm{j}}(j=0,1,2,3)$, by using Eq. (2) to fit experimental results of indoor bacterial and fungal concentrations in each scenario. Before the start of each scenario, the AER of the room was measured by the tracer gas decay method using $\mathrm{CO}_{2}(99.99 \%$ purity; Air Liquide) as the tracer gas. The $\mathrm{CO}_{2}$ concentration was measured by a $\mathrm{CO}_{2}$ meter (CM-0212; CO2Meter) at an interval of 20 seconds. Surface sampling was conducted on the first and the last day of each scenario to quantify bacterial and fungal loadings on the indoor floor surface for estimating the contribution of their resuspension from the floor to indoor bioaerosol pollution. When the surface sampling was conducted, nine targeted sampling areas, which were evenly distributed on the floor area of the indoor space, were sampled using nine different swab kits. Due to the fact that the deposition velocity of indoor airborne bacteria and fungi is several magnitudes less than one, as shown in Table 1, their surface loadings on the floor can be assumed to be independent of their indoor concentrations during the air sampling experiment. In addition, the surface loadings are assumed to be constant during the air sampling due to the constant indoor supply air flow rate and activities of occupants in the tutorial room.

In Scenario 1, there was no occupant in the room and a HEPA filter was inserted at connection between the fresh air duct and the AC unit to prevent the introduction of outdoor bioaerosols through the mechanical ventilation and the emanation of bioaerosols from the fresh air duct. Hence, besides the resuspension from the floor (a common source in all scenarios), the bioaerosol emanation from the $\mathrm{AC}$ unit was the only emission source in this scenario. When Eq. (2) was applied to Scenario $1, E_{0}=E_{1}=E_{3}=0$. As a result, the bioaerosol emanation rate of the $\mathrm{AC}$ unit $\left(E_{2}\right)$ became the only unknown. Using the solution expressed by Eq. (2) to fit the experimental data from Scenario 1 through the nonlinear least squares method, the emanation rates of the AC unit $\left(E_{2}\right)$ for bacteria and fungi could be found.

Scenario 2 was largely similar to Scenario 1 but with addition of two occupants. Prior to Scenario 2, there were no occupants in the experimental room for 11 days. Applying Eq. (2) to Scenario 2, and using the $E_{2}$ determined from
Scenario $1, E_{0}=E_{3}=0$, the bioaerosol emission from the occupants $\left(E_{1}\right)$ was the only unknown in the equation. Using a similar fitting method for the experimental results obtained in Scenario 2, $E_{1}$ for bacteria and fungi could be determined.

In Scenario 3, the HEPA filter was moved to the fresh air intake to prevent the introduction of outdoor bioaerosols through the mechanical ventilation. However, this allowed for the bioaerosols emanated from the fresh air duct to enter the room. For Scenario 3, $E_{0}=0$ in Eq. (2(c)). $E_{1}$ and $E_{2}$ were already determined from Scenario 1 and 2 . The only unknown, the bioaerosol emanation rate of the fresh air duct $\left(E_{3}\right)$, could be determined by fitting the experimental results obtained in Scenario 3 with Eq. (2) using the non-linear least squares method. Consequently, the bioaerosol emanation rate from the fresh air duct could be calculated.

In Scenario 4, the HEPA filter was removed. This scenario bore the closest resemblance to the actual operating condition of the room under ACMV mode. After determining $E_{1}, E_{2}$ and $E_{3}$ from the previous scenarios, $E_{0}$ (the rate of supply of bioaerosols from outdoors through mechanical ventilation) became the only unknown parameter in Eq. (2(c)) for Scenario 4. Using a similar data fitting method based on Scenario 4's air sampling data, $E_{0}$ could be quantified.

Table 2 summarises the sources/sinks of indoor bioaerosols in each scenario. The contribution to indoor bioaerosol levels by the occupants can be illustrated by comparing Scenarios 1 and 2. Comparing Scenarios 2 and 3 and between Scenarios 3 and 4 reveal the contribution by the fresh air duct and the introduction of outdoor bioaerosols through the mechanical ventilation, respectively.

Two additional scenarios (Scenarios 5 and 6, as shown in Fig. 2) were defined to study the impact of the AC unit on indoor bioaerosol levels. In Scenario 5, the AC unit was disconnected from the fresh air duct, i.e., fresh air was supplied directly to the room without going through the $\mathrm{AC}$ unit. A standing fan was used to maintain indoor air mixing and thermal comfort. The air flow rate of the fan was $0.35 \mathrm{~m}^{3} \mathrm{~s}^{-1}$, which was similar to the return air flow rate of the $\mathrm{AC}$ unit $\left(0.37 \mathrm{~m}^{3} \mathrm{~s}^{-1}\right)$. On this basis, the deposition velocity and the resuspension rate of indoor bioaerosols in this scenario were assumed to be the same as those in the other scenarios.

The AC unit could impact indoor bioaerosol levels in two ways, bioaerosol emanation or removal by its return air filter. In Scenarios 1-4, the AC unit operated with the return air filter and contributed to indoor bioaerosol levels through these two mechanisms. Comparing Scenario 5 with Scenario 4 reveals the net effect of the AC unit on indoor bioaerosol levels. Scenario 6 was designed to further investigate the breakdown of these two mechanisms. In Scenario 6, the 

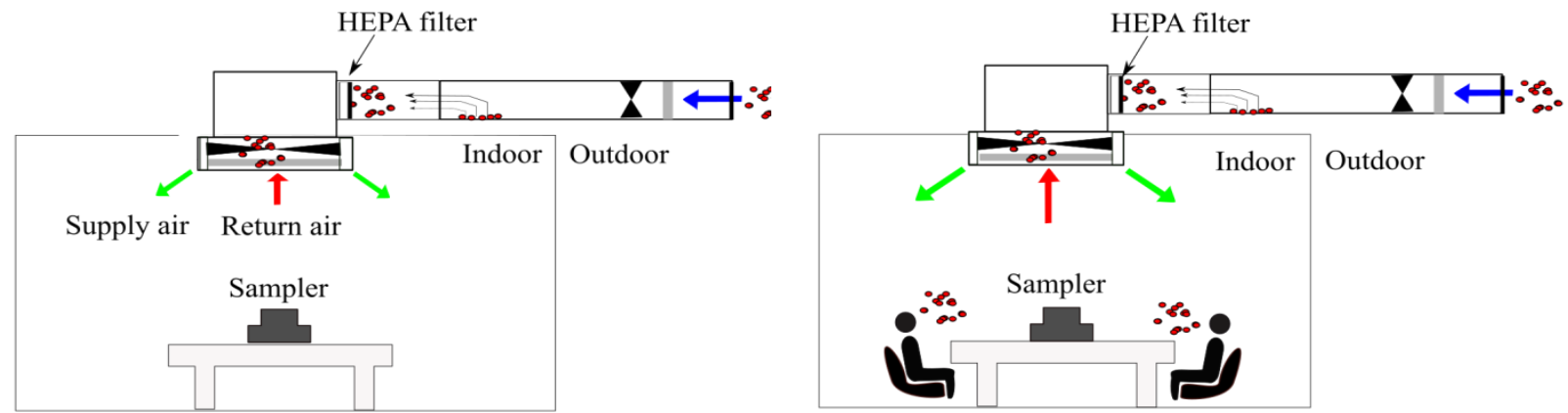

Scenario 1

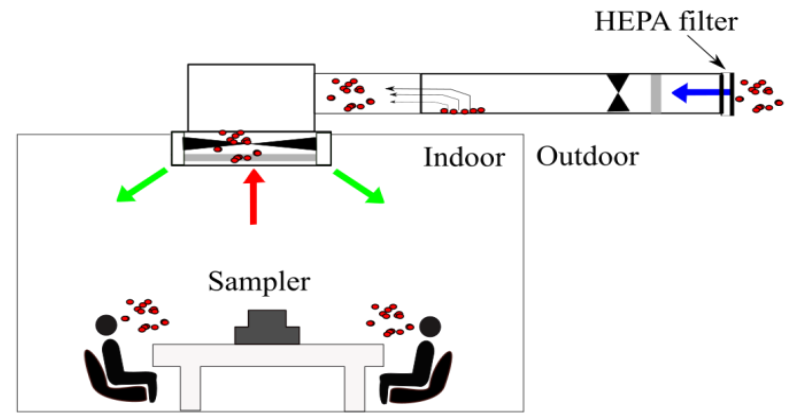

Scenario 3

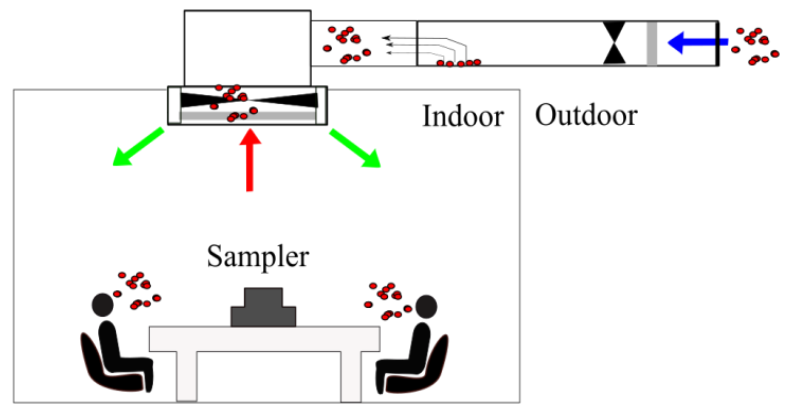

Scenario 4

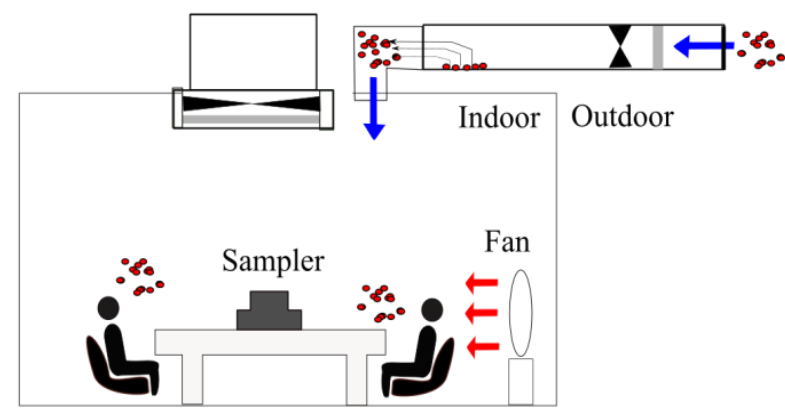

Scenario 5

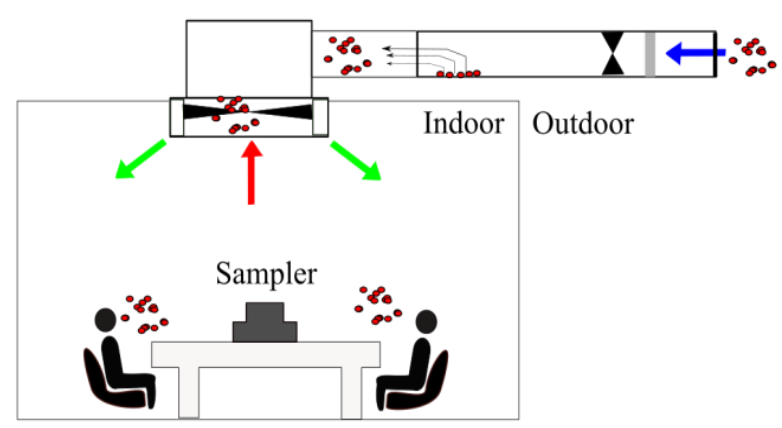

Scenario 6

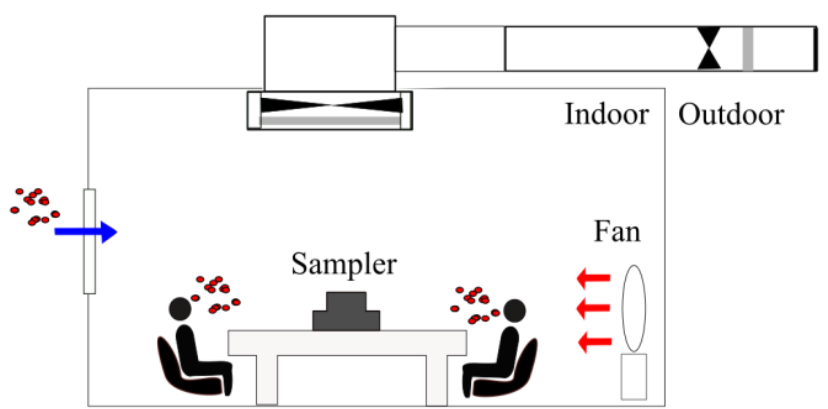

Scenario 7

Fig. 2. Experimental setup for the seven scenarios.

conditions were almost the same as those in Scenario 4 except that the return air filter in the AC unit was removed. The difference in indoor bioaerosol concentrations between Scenario 5 and Scenario 6 will reflect the effects of bioaerosol emanation from the $\mathrm{AC}$ unit without the filtration effect of the return air filter.

In the last scenario, Scenario 7, the room was naturally ventilated (the window was opened, and the AC unit was switched off) with the same standing fan used in Scenario 5 to provide thermal comfort. Scenario 7 represented the condition of the room under natural ventilation mode. The comparison between Scenario 7 and Scenario 4 reveals the relative efficacy of controlling indoor bioaerosol levels between the natural ventilation mode and the ACMV mode.

After air sampling experiment in a day, the indoor floor area of the tutorial room was mopped with clean water by a researcher to simulate the daily cleaning of the floor in the tutorial room on weekdays. From Scenario 1 to Scenario 4 
Table 2. Details of indoor bioaerosol sources in the experimental scenarios.

\begin{tabular}{|c|c|c|c|c|c|c|c|}
\hline & \multirow[b]{3}{*}{ AER } & \multicolumn{6}{|c|}{ Sources/sinks of indoor bioaerosols } \\
\hline & & \multirow{2}{*}{$\begin{array}{l}\text { Introduction of } \\
\text { outdoor bioaerosols } \\
\text { through ventilation } \\
\left(E_{0}\right)\end{array}$} & \multirow{2}{*}{$\begin{array}{l}\text { Number of } \\
\text { human } \\
\text { occupants } \\
\left(E_{1}\right)\end{array}$} & \multicolumn{2}{|c|}{ AC unit } & \multirow[b]{2}{*}{$\begin{array}{l}\text { Fresh } \\
\text { air duct } \\
\left(E_{3}\right)\end{array}$} & \multirow[b]{2}{*}{ Window } \\
\hline & & & & $\begin{array}{l}\text { Emanation } \\
\left(E_{2}\right)\end{array}$ & $\begin{array}{l}\text { Filtration by } \\
\text { RAF } \\
\left(\eta_{1}\right)\end{array}$ & & \\
\hline Scenario 1 & 0.516 & No & 0 & Yes & Yes & No & Closed \\
\hline Scenario 2 & 0.516 & No & 2 & Yes & Yes & No & Closed \\
\hline Scenario 3 & 0.588 & No & 2 & Yes & Yes & Yes & Closed \\
\hline Scenario 4 & 0.69 & Yes & 2 & Yes & Yes & Yes & Closed \\
\hline Scenario $5^{\mathrm{a}}$ & 0.69 & Yes & 2 & No & No & Yes & Closed \\
\hline Scenario $6^{\mathrm{b}}$ & 0.69 & Yes & 2 & Yes & No & Yes & Closed \\
\hline Scenario 7 & 1.63 & Yes & 2 & No & No & No & Open \\
\hline
\end{tabular}

a The AC unit is switched off and disconnected from the fresh air duct.

$\mathrm{b}$ The filter in the AC unit is taken off.

RAF: return air filter; AER: air exchange rate $\left(\mathrm{h}^{-1}\right)$.

Bioaerosol resuspension from the floor occurs in all scenarios.

and in Scenario 6, which were operated under air-conditioning, the ACMV system was switched on at 9 AM and off at 5 PM in a day. In these scenarios, indoor temperature ranged from 24 to $25^{\circ} \mathrm{C}$ while indoor relative humidity ranged from $64 \%$ to $68 \%$ during the experiment. In Scenario 5 and Scenario 7 , which were not operated under air-conditioning, indoor temperature ranged from 27 to $28^{\circ} \mathrm{C}$ while indoor $\mathrm{RH}$ was around $70 \%$ during the experiment. In Scenario 7, which was operated in the natural ventilation mode, the window was opened at $9 \mathrm{AM}$ and closed at $5 \mathrm{PM}$ in a day. Average indoor temperature and $\mathrm{RH}$ during the experiment in each scenario are shown in Table S1. The experiments were conducted from June to September 2016, which was within the southwest monsoon season in Singapore, to minimise the influence of climate change on the differences of indoor bioaerosol concentrations between the scenarios.

\section{Species Identification of Bioaerosols}

In order to identify the species of the viable bacteria and fungi emanated from the ACMV system, air sampling was conducted in two settings. In the first setting (Fig. 3(a)), an impactor (sampler) was placed at the end of the fresh air duct and connected with a reducer to isokinetically collect the bioaerosols emanated from the fresh air duct while a HEPA filter was installed at the fresh air intake to prevent the introduction of outdoor bioaerosols through the mechanical ventilation. As a result, only the bioaerosols emanated from the fresh air duct was collected by the sampler. In the second setting (Fig. 3(b)), the AC unit was disconnected from the fresh air duct. A chamber was tightly connected to the return air grill of the AC unit, and tapes were used to seal the gaps between the chamber and the return air grill. Pure nitrogen gas was introduced into the chamber to free the return 'air' from bioaerosols. Subsequently, a sampler was used together with the reducer to isokinetically collect the bioaerosols in the supply air, which only carried the bioaerosols emanated from the AC unit.

Air sampling was conducted in batches of 12 samples. After finishing a batch, the samples were sent for incubation using the same method as described in Supplemental Material.
The colonies on the incubated samples were then analysed based on their morphological characteristics using standard taxonomic keys (Fotedar et al., 1991; Xu et al., 2008). This process continued until no colony of new morphological characteristics was observed in the latest batch. This was to ensure that all possible species were included. These agar plates were sent for species identification by the DNA sequencing method. To briefly summarise, gDNA of the colonies was first extracted after incubation, and PCR reaction was subsequently performed to obtain the PCR product. The PCR product is the fungal internal transcribed spacer (ITS) and bacterial 16s rRNA, which were targeted for the DNA sequence analysis following the method described in Luhung et al. (2017).

\section{RESULTS}

\section{Impacts of Bioaerosol Emanation from ACMV System on Indoor Concentration}

Average indoor bioaerosol concentrations from the seven scenarios are shown in Fig. 4. The averages are taken from all the air samples collected in five days ( 75 air samples for bacterial cultivation and 75 samples for fungal cultivation) of air sampling experiment for each scenario. The average indoor bacterial concentration in Scenario 2 was about twice that of Scenario 1, while their difference in fungal concentration was statistically insignificant $(p>0.05)$. This suggests that the occupants contributed significantly to the airborne bacterial concentration but had a minor impact on the fungal concentration indoors.

The average bacterial and fungal concentrations in Scenario 3 were significantly $(\mathrm{p}<0.05)$ higher than their counterparts in Scenario 2, which indicated the fresh air duct as a possible source of airborne bioaerosols. Surfaces of the fresh air duct were loaded with bacteria and fungi, which could have originated from the deposition or growth of deposited microorganisms on the duct surfaces (Batterman and Burge, 1995; Bluyssen et al., 2003). Subsequently, the microorganisms on surfaces of the fresh air duct could be resuspended to form bioaerosols and transported indoors (Zhou et al., 2011; You and Wan, 2014). 


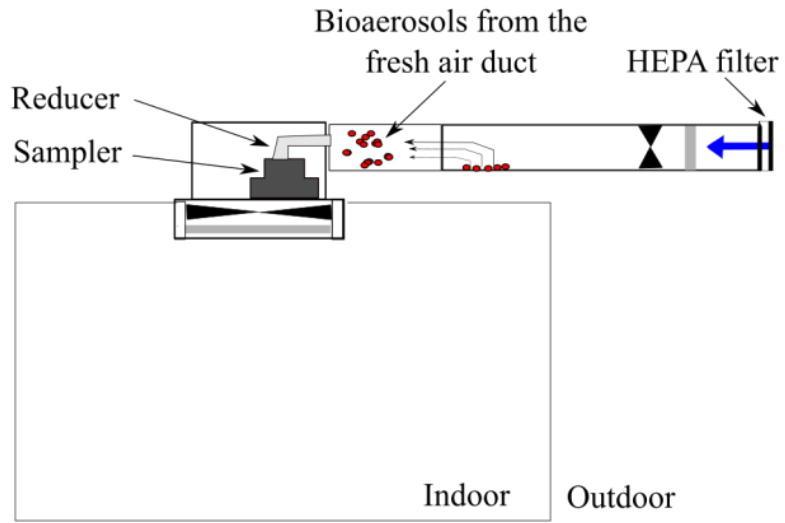

(a)

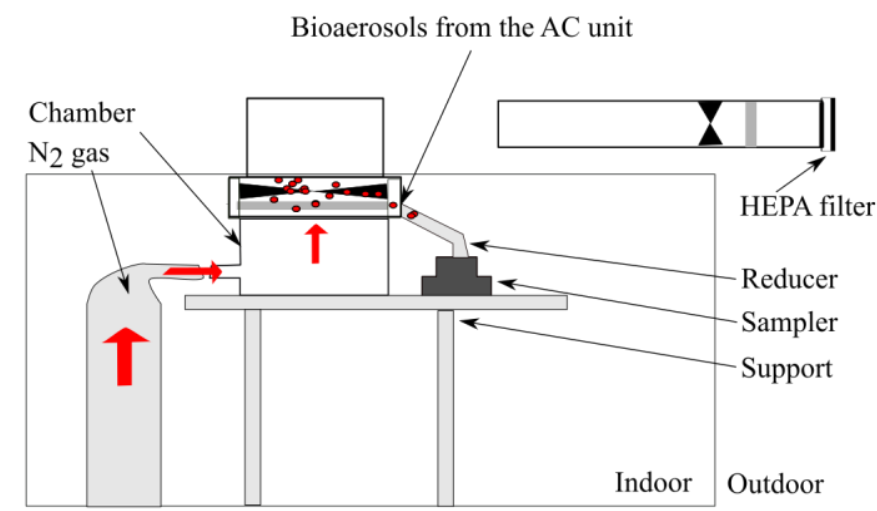

(b)

Fig. 3. Experimental setup for species identification. Bioaerosol sampling in (a) the fresh air duct and (b) the AC unit.

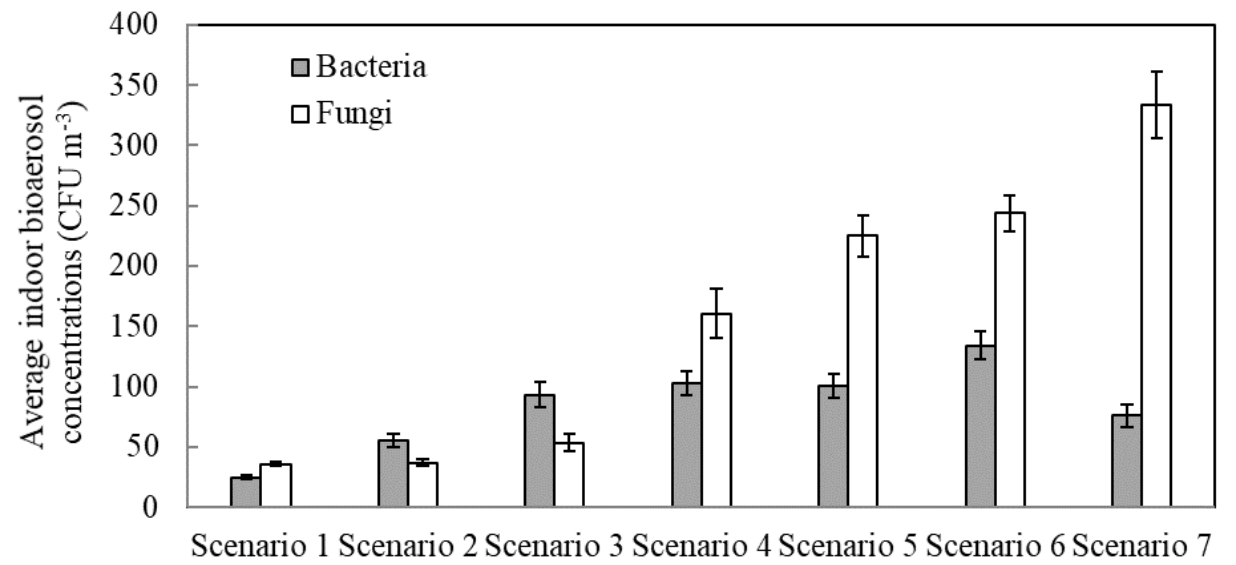

Fig. 4. Average indoor bioaerosol concentrations. Error bars show the standard error of mean from the five days' samples.

The difference in the average bacterial concentrations between Scenario 3 and 4 was statistically insignificant ( $p>0.05$ ). However, the average fungal concentration in Scenario 4 was almost triple that of Scenario 3. This suggested that the fresh air intake had minor impacts on the bacterial concentration but was a major (or even the dominant) contributor to the indoor fungal concentration. It is also worth noting that this significant introduction of fungi from outdoors through the mechanical ventilation was observed even though there was a MERV-8 rating filter installed in the fresh air duct.

The difference in the average bacterial concentration between Scenario 5 and Scenario 4 was also statistically insignificant $(p>0.05)$. However, the fungal concentration in Scenario 5 was $47 \%$ higher than that in Scenario 4. This indicated that the $\mathrm{AC}$ unit had a significant effect on removing fungi but had a minor effect on removing bacteria. Both the average bacterial and fungal concentrations in Scenario 6 were significantly higher than those in Scenario 5 ( $\mathrm{p}<0.05)$. This indicated the net effect of bioaerosol emanation from the AC unit (without removal of bioaerosols by the return air filter).

Scenario 4 (ACMV mode) had a significantly lower average fungal concentration $(p<0.05)$ than Scenario 7 (natural ventilation mode). The average bacterial concentration in Scenario 4 was about $30 \%$ higher than that in Scenario 7. This indicated that the ACMV mode was effective in controlling the fungal level but led to a higher bacterial level as compared to natural ventilation. This was caused by the bioaerosol emanation from the ACMV system and will be further investigated in subsequent sections. The measured AER in the natural ventilation mode was about double of that in the ACMV mode, leading to a higher introduction of outdoor fungi through the ventilation in the former.

\section{Bioaerosol Emanation Rates}

The average bacterial loading on the floor of the seven scenarios was calculated to be $2.6 \times 10^{5} \mathrm{CFU} \mathrm{m^{-2 }}$ by averaging all the measurement results of bacterial loadings from the seven scenarios (126 surface samples in total), and the average fungal loading was calculated to be $1.8 \times 10^{4}$ CFU $\mathrm{m}^{-2}$ using the same method. As shown in Table S2, variation of both the bacterial and fungal loadings on the floor of the seven scenarios were insignificant, which might be due to the constant supply air flow rate, the constant indoor activity during the experiment and the regular cleaning after every day's experiment. Therefore, the calculated average bacterial and fungal loadings on the floor of the seven scenarios are used as their floor surface loading $N_{\text {floor }}$ in Eq. (1). As an initial estimate, the rate of bioaerosol resuspension from the 
floor $\left(R_{\text {floor }} N_{\text {floor }} A\right)$ was calculated to be $0.024 \mathrm{CFU} \mathrm{s}^{-1}$ for bacteria and $0.003 \mathrm{CFU} \mathrm{s}^{-1}$ for fungi.

Using Eq. (2) to fit the experimental data from Scenario 1 through the non-linear least squares method, the emanation rates of the $\mathrm{AC}$ unit $\left(E_{2}\right)$ for bacteria and fungi were found to be $0.87 \mathrm{CFU} \mathrm{s}^{-1}$ and $2.96 \mathrm{CFU} \mathrm{s}^{-1}$, respectively. The experimental results of Scenario 1 and the fitted curve of Eq. (2) are shown in Fig. S1.

Using a similar fitting method for the experimental results obtained in Scenario 2 (Fig. S2), $E_{1}$ for bacteria and fungi were determined to be $1.11 \mathrm{CFU} \mathrm{s}^{-1}$ and $0.07 \mathrm{CFU} \mathrm{s}^{-1}$, respectively. Since there were two occupants in the current experimental setting, it could be estimated that the contribution from each occupant to bacteria is at a rate of $0.56 \mathrm{CFU} \mathrm{s}^{-1}$ and fungi at a rate of $0.035 \mathrm{CFU} \mathrm{s}^{-1}$.

The bioaerosol emanation rate of the fresh air duct $\left(E_{3}\right)$ could be determined by fitting the experimental results obtained in Scenario 3 (Fig. S3) with Eq. (2) using the nonlinear least squares method. Consequently, the emanation rate from the fresh air duct were calculated as $1.53 \mathrm{CFU} \mathrm{s}^{-1}$ and $0.94 \mathrm{CFU} \mathrm{s}^{-1}$ for bacteria and fungi, respectively.

After determining $E_{1}, E_{2}$ and $E_{3}$ from the previous scenarios, $E_{0}$ (the rate of supply of bioaerosols from outdoors through the mechanical ventilation) became the only unknown parameter in Eq. (2) for Scenario 4. Using a similar data fitting method based on Scenario 4's air sampling data (Fig. S4), $E_{0}$ was calculated to be $1.64 \mathrm{CFU} \mathrm{s}^{-1}$ for bacteria and 8.48 CFU s ${ }^{-1}$ for fungi.

Bioaerosol emanation rates $E_{0}, E_{1}, E_{2}$ and $E_{3}$, determined by experimental data fitting method described above, and the bioaerosol emanation rate due to resuspension from the floor are summarised in Fig. 5. The result showed that the introduction of outdoor fungi through the mechanical ventilation $\left(E_{0}\right)$ served as the dominant source of indoor airborne fungi. The second largest contributor to indoor airborne fungi was the emanation from the $\mathrm{AC}$ unit $\left(E_{2}\right)$, but the emanation rate is smaller than $E_{0}$ by a large margin. The combined fungal emanation rate from the sources related to the ACMV system $\left(E_{2}+E_{3}\right)$ was only about half of $E_{0}$. This echoed the observation from air sampling data (comparison between Scenario 4 and 7; Fig. 4) that using the ACMV system was an effective measure to reduce indoor airborne fungal level, compared to natural ventilation.

Emanation rates of bacteria from the four sources $\left(E_{0}, E_{1}\right.$, $E_{2}$ and $\left.E_{3}\right)$ in the current experimental setting were of similar magnitude. The combined bacterial emanation rate due to ACMV-related sources $\left(E_{2}+E_{3}\right)$ outweighed the emanation rate due to the introduction of outdoor bacteria through the mechanical ventilation $\left(E_{0}\right)$. It suggested that using the ACMV system could lead to higher indoor airborne bacterial concentration compared to natural ventilation. This matches the observation from air sampling data (comparison between Scenario 4 and 7; Fig. 4). The occupant density in the current experimental setting was $18 \mathrm{~m}^{2}$ person ${ }^{-1}$, similar to the typical office environment of $20 \mathrm{~m}^{2}$ person $^{-1}$ (Kim and Haberl, 2012). However, for indoor environments with higher occupant densities, e.g., classrooms (2.9-4 $\mathrm{m}^{2}$ person $\left.^{-1}\right)$ or shopping malls $\left(2.5 \mathrm{~m}^{2}\right.$ person $\left.{ }^{-1}\right)$ (ASHRAE, 2004), bacteria emanation from occupants is expected to become the dominant source for indoor airborne bacteria.

\section{Species of Bioaerosol Emanated from the ACMV System}

The species of bioaerosol samples collected from the fresh air duct (Fig. 3(a)) and those collected from the AC unit (Fig. 3(b)) were identified using the DNA sequencing method. The identified bacterial and fungal species are shown in Figs. 6 and 7, respectively. A number of 24 bioaerosol species from the fresh air duct and that of 39 bioaerosol species from the AC unit were identified. The number of bacterial species identified in the fresh air duct is close to that identified in the AC unit. In contrast, many more fungal species were identified in the AC unit than that identified in the fresh air duct, as shown in Fig. 7. A possible reason is that the fresh air duct is only exposed to fresh air

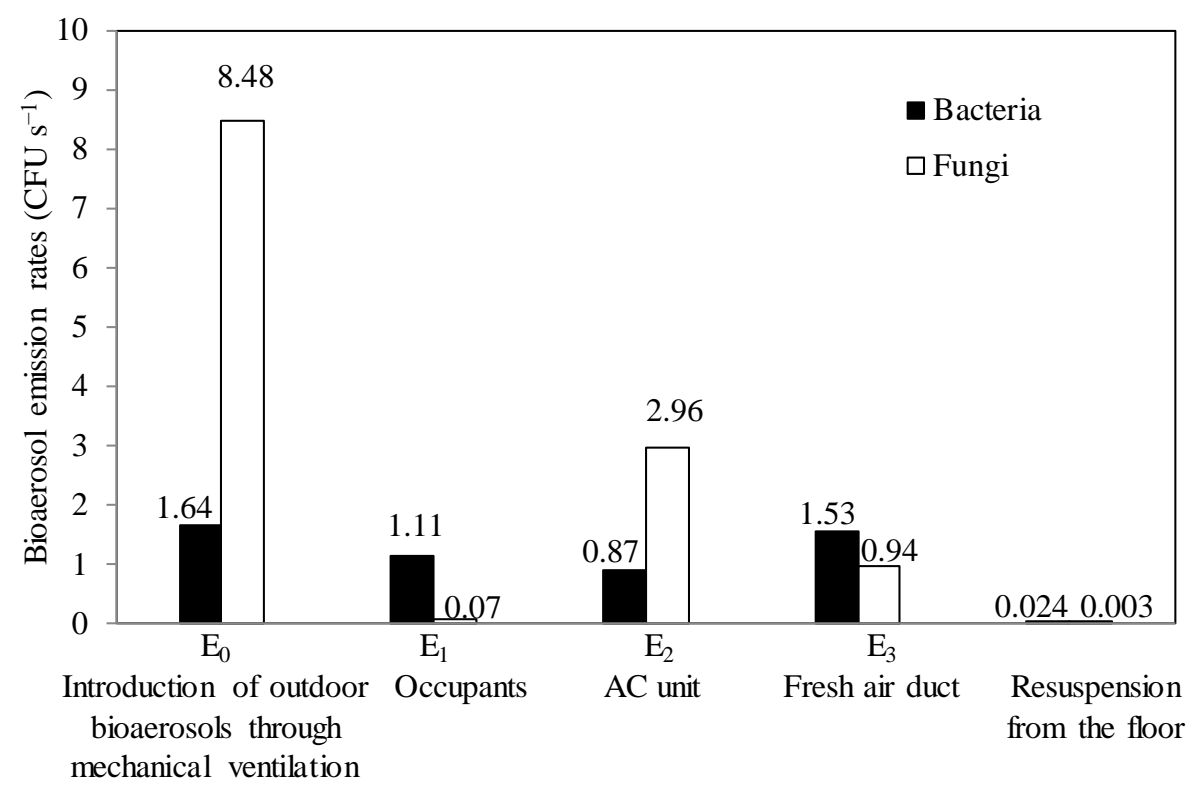

Fig. 5. Estimated bioaerosol emanation rates of bioaerosol sources. 


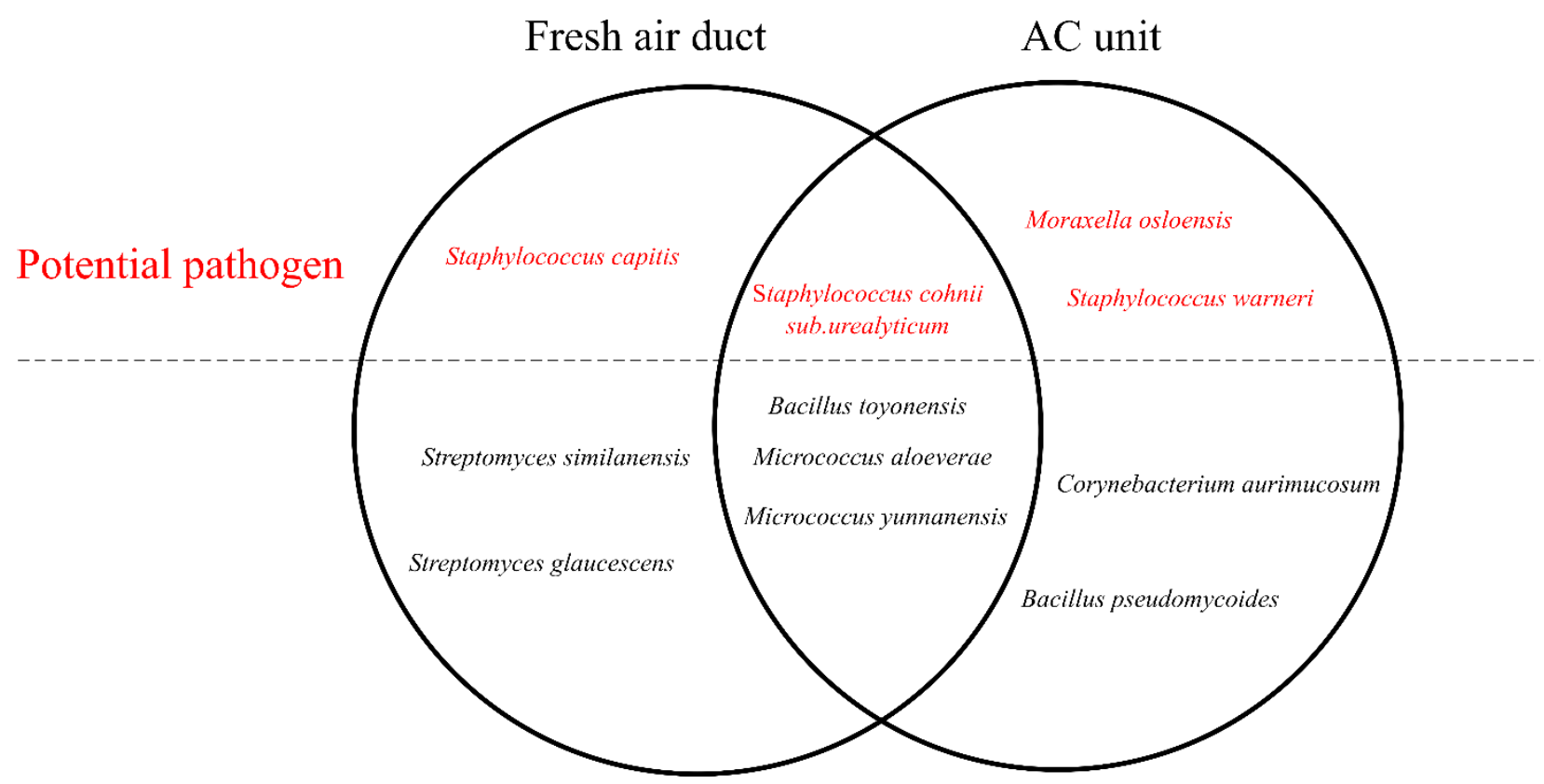

Fig. 6. Identified bacterial species emanated from the ACMV system.

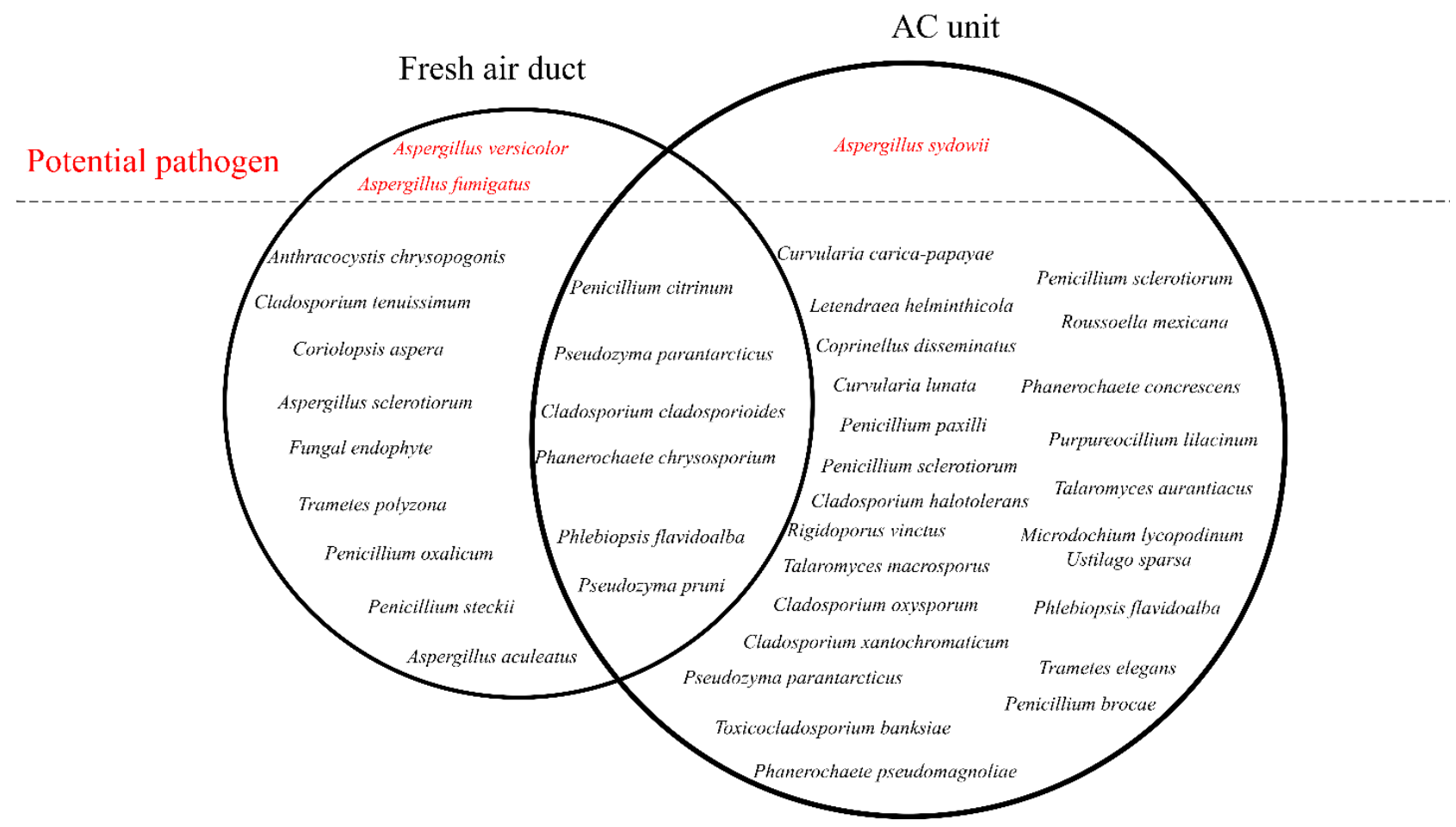

Fig. 7. Identified fungal species emanated from the ACMV system.

whereas the AC unit is exposed to both the fresh air and the room return air. The room return air could contain more fungal species that are not in the fresh air, e.g., species shed from the occupants.

Some of the identified bacterial and fungal species are potential pathogenic species, as listed in the Updated Biological Agents and Toxins List (Ministry of Health Singapore, 2017). Among the identified bacterial species, three species in the Staphylococcus genera, Staphylococcus cohnii sub. urealyticum, which can cause catheters and urinary tract infection in immunocompromised patients (Shahandeh et al., 2015); Staphylococcus warneri, which might cause catheter-related infection (Kamath et al., 1992); and Staphylococcus capitis, which might cause prosthetic joint infection (Tevell et al., 2017), were found in the bioaerosol emanation from the ACMV system. A potential pathogenic bacterial species, Moraxella osloensis, which populate on the skin and mucosa of humans (Yamada et al., 
2019), was only observed to be emanated from the AC unit, suggesting its transportation from occupants through room air recirculation and accumulation in the ACMV system.

All the potential pathogenic fungal species found in the ACMV system belong to the Aspergillus genera. Aspergillus fumigatus, which was found to be emanated from the fresh air duct, is a listed potential pathogenic fungal species (Ministry of Health Singapore, 2017). Despite not being listed, the other two species from this genera, Aspergillus sydowii and Aspergillus versicolor, were also reported to be associated with several human diseases including the building-associated pulmonary diseases (Hodgson et al., 1998; Liu et al., 2017). The results of species identification indicate that potential pathogens, including those emanated from occupants, could accumulate in the ACMV system and subsequently be transported into the indoor space.

\section{DISCUSSION}

\section{Mitigation of Indoor Bioaerosol Pollution by ACMV Cleaning}

Results of the current study show that the ACMV system can be a significant source of indoor bioaerosols, especially bacteria. In order to investigate the potential mitigation of indoor bioaerosol pollution by better cleaning of the ACMV system, three hypothetical cases were simulated using Eq. (2):

1. Bioaerosol emanation of the fresh air duct was removed by setting $E_{3}=0$ (HYPO 1), simulating a cleaning of the fresh air duct. For bacteria, $E_{0}=1.64 \mathrm{CFU} \mathrm{s}{ }^{-1}, E_{1}=1.11$ $\mathrm{CFU} \mathrm{s}^{-1}, E_{2}=0.87 \mathrm{CFU} \mathrm{s}^{-1}$. For fungi, $E_{0}=8.48 \mathrm{CFU} \mathrm{s}^{-1}$, $E_{1}=0.07 \mathrm{CFU} \mathrm{s}^{-1}, E_{2}=2.96 \mathrm{CFU} \mathrm{s}^{-1}$.

2. Bioaerosol emanation of the $\mathrm{AC}$ unit was removed by setting $E_{2}=0$ (HYPO 2), simulating a cleaning of the AC unit. For bacteria, $E_{0}=1.64 \mathrm{CFU} \mathrm{s}^{-1}, E_{1}=1.11 \mathrm{CFU} \mathrm{s}^{-1}$, $E_{3}=1.53 \mathrm{CFU} \mathrm{s}^{-1}$. For fungi, $E_{0}=8.48 \mathrm{CFU} \mathrm{s}^{-1}, E_{1}=$ $0.07 \mathrm{CFU} \mathrm{s}^{-1}, E_{3}=0.94 \mathrm{CFU} \mathrm{s}^{-1}$.

3. Bioaerosol emanation of the ACMV system was removed by setting $E_{2}=E_{3}=0$ (HYPO 3), simulating a cleaning of the entire ACMV system. For bacteria, $E_{0}=$ $1.64 \mathrm{CFU} \mathrm{s}^{-1}, E_{1}=1.11 \mathrm{CFU} \mathrm{s}^{-1}$. For fungi, $E_{0}=8.48$ $\mathrm{CFU} \mathrm{s}^{-1}, E_{1}=0.07 \mathrm{CFU} \mathrm{s}^{-1}$.

The environmental parameters described before were used in this simulation. The AER and the bioaerosol emanation rates of sources in Scenario 4 were used as inputs for the simulation. These inputs are summarised in Tables 1 and 2. The three hypothetical cases were compared to the fitting of air sampling data obtained in Scenario 4 using Eq. (2), which was used as the reference case in this comparison due to the fact that this scenario bore the closest resemblance to the actual operating condition of the room under ACMV mode. The five-day average indoor bioaerosol concentration at 9:30 AM in Scenario 4 was used as the initial bioaerosol concentration $C_{0}$ in the simulation $\left(132.86 \mathrm{CFU} \mathrm{m}^{-3}\right.$ for bacteria and $372.20 \mathrm{CFU} \mathrm{m}^{-3}$ for fungi). Simulation results are shown in Fig. 8.

Compared to the reference case (Scenario 4), daily integrated average indoor airborne bacterial concentration drops by $28 \%$ in HYPO 1, 17\% in HYPO 2 and $45 \%$ in HYPO 3. Similarly, daily integrated average indoor airborne fungal concentration drops by $8 \%$ in HYPO $1,26 \%$ in HYPO 2 and $34 \%$ in HYPO 3. The results indicate that significant mitigation of indoor bioaerosol pollution can be achieved if the hygiene of the ACMV system is improved. The air sampling results discussed in earlier sections suggested that the ACMV mode leads to a higher indoor airborne bacterial concentration compared to the natural ventilation mode. A major contributor to that is the bacterial emanation from the ACMV system ( $E_{2}$ and $\left.E_{3}\right)$. The HYPO 3 simulation results show that when the bioaerosol emanation from the ACMV system is removed, the average indoor airborne bacterial concentration will drop to about $50 \mathrm{CFU} \mathrm{m}^{-3}$, which is around $30 \%$ less than the average indoor airborne bacterial concentration under natural ventilation in Scenario 7 (about $72 \mathrm{CFU} \mathrm{m}^{-3}$ ).

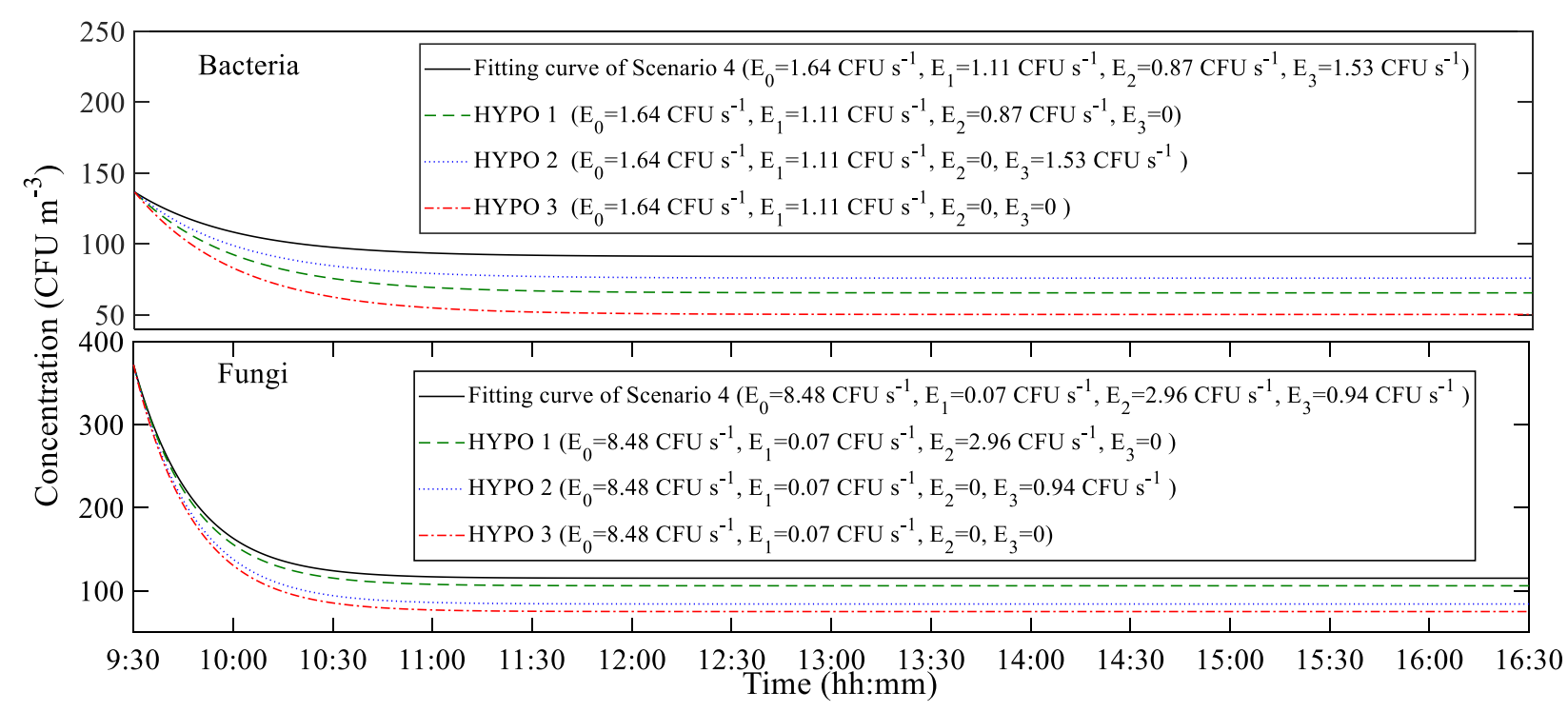

Fig. 8. Indoor bioaerosol concentrations $\left(\mathrm{CFU} \mathrm{m}{ }^{-3}\right)$ in the three hypothetical cases and the reference case (fitting of Scenario 4). 


\section{Limitations}

In this study, the culture-based method is employed, and this method is limited to the investigation of the viable portion of bioaerosols. However, non-viable bioaerosols can also cause health problems, and the investigation of the nonviable portion of bioaerosol emanation from ACMV systems is needed to have a comprehensive understanding of its role as a bioaerosol source. Further study should be conducted to investigate the contamination and emanation of non-viable bioaerosols from ACMV systems.

The accuracy of the culture-based method is largely limited by colony formation. Since the impactor used has 200 holes, the maximum number of colonies countable on a sampling plate is 200 . Too long a sampling time could cause overlapping of colonies on the sampling plate whereas too short a sampling time could lead to too few numbers of colonies on the sampling plate and thus high level of error (Sutton, 2011). This study used a sampling time of 10 minutes which gave colony counts ranging from 25 to 200 on most of the sampling plates, as recommended by Sutton (2011).

In the experimental room, the existence of bioaerosol sources might lead to a spatial inhomogeneity of indoor bioaerosol concentrations from Scenario 1 to 4 , where the experimental data was used to quantify the contribution of bioaerosol sources using the indoor bioaerosol model with a well-mixed assumption (Eq. (1)). From Scenario 1 to 4, the experimental room had a relatively low air exchange rate $\left(0.516-0.6 \mathrm{~h}^{-1}\right)$ combined with a relatively high air recirculation rate (around $13 \mathrm{~h}^{-1}$ ), suggesting that the indoor air convection could rapidly and effectively mix the indoor air during the seven hours' experiment in a day (Nazaroff and Cass, 1986) in these scenarios. In addition, bioaerosol concentration gradient due to deposition and resuspension only exists very close to the indoor surfaces (Lai and Nazaroff, 2000), indicating a reasonable hypothesis that the indoor bioaerosols were well mixed.

\section{CONCLUSION}

Bioaerosol emanation from an ACMV system and its impact on indoor pollution was investigated experimentally in an indoor environment in tropical Singapore. Surface and air sampling were conducted, followed by culture-based and species analyses. Bioaerosol species originating from both outdoor and indoor sources, including potentially pathogenic species emanating from occupants (Moraxella osloensis), were found in the ACMV system, indicating its role as a potential source. Specifically, pathogens can deposit and accumulate in this system through fresh air intake and room air recirculation and then emanate indoors. The dominant source of indoor airborne fungi is the outdoor fungi introduced through mechanical ventilation, which equals approximately double the amount emitted from the ACMV system, as supported by the fact that the average indoor airborne fungal concentration measured during ACMV mode is approximately half of that measured during natural ventilation mode. However, the ACMV system emits the largest contribution to the indoor airborne bacteria, exceeding that of the outdoor bacteria introduced through mechanical ventilation, bacterial emanation from occupants or resuspended bacteria from the floor. The air sampling results suggest that operating the room in ACMV mode produces a higher indoor airborne bacterial concentration (by 30\%) than natural ventilation mode. Although the occupants emanate a significant amount of bacteria, their fungal emanation is minimal. By cleaning the ACMV system, the indoor airborne fungal and bacterial concentrations can be reduced by $34 \%$ and $45 \%$, respectively. Additionally, maintaining and operating a clean system leads to lower fungal and bacterial concentrations than using natural ventilation.

\section{ACKNOWLEDGEMENTS}

This work was funded by the Republic of Singapore's Ministry of Education through Grant No. RG190/14 and MOE2016-T2-1-063 as well as the Republic of Singapore's National Research Foundation through a grant to the Berkeley Education Alliance for Research in Singapore (BEARS) for the Singapore-Berkeley Building Efficiency and Sustainability in the Tropics (SinBerBEST) Program.

\section{SUPPLEMENTARY MATERIAL}

Supplementary data associated with this article can be found in the online version at http://www.aaqr.org.

\section{REFERENCES}

ASHRAE (2004). ANSI/ASHRAE Standard 62.1-2010. Ventilation for Acceptable Indoor Air Quality. American Society of Heating, Refrigerating and Air-Conditioning Engineers, Inc., Atlanta.

ASHRAE (2017). ANSI/ASHRAE Standard 52.2-2017. Method of testing general ventilation air cleaning devices for removal efficiency by particle size. American Society of Heating, Refrigerating and Air-Conditioning Engineers, Inc., Atlanta.

Aziz, A.A., Sumiyoshi, D. and Akashi, Y. (2017). Low cost humidity controlled air-conditioning system for building energy savings in tropical climate. J. Build. Eng. 11: 916.

Batterman, S.A. and Burge, H. (1995). Hvac systems as emission sources affecting indoor air quality: A critical review. HVAC\&R Res. 1: 61-78.

Beck, J.M., Young, V.B. and Huffnagle, G.B. (2012). The microbiome of the lung. Transl. Res. 160: 258-266.

Berrington, W.R. and Hawn, T.R. (2013). Human Susceptibility to Legionnaires' Disease. In Legionella, Springer, pp. 541-551.

Bluyssen, P.M., Cox, C., Seppänen, O., de Oliveira Fernandes, E., Clausen, G., Müller, B. and Roulet, C.A. (2003). Why, when and how do HVAC-systems pollute the indoor environment and what to do about it? The European AIRLESS project. Build. Environ. 38: 209225.

Bonetta, S., Bonetta, S., Mosso, S., Sampò, S. and Carraro, E. (2010). Assessment of microbiological indoor air quality in an Italian office building equipped with an 
HVAC system. Environ. Monit. Assess. 161: 473-483.

Burroughs, H.B. (2005). Filtration and Building Security. ASHRAE J. 47: 24.

Chen, A. and Chang, V.W.C. (2012). Human health and thermal comfort of office workers in Singapore. Build. Environ. 58: 172-178.

Chen, A., Cao, Q., Zhou, J., Yang, B., Chang, V.W.C. and Nazaroff, W.W. (2016). Indoor and outdoor particles in an air-conditioned building during and after the 2013 haze in Singapore. Build. Environ. 99: 73-81.

Cheong, K. and Lau, H. (2003). Development and application of an indoor air quality audit to an air-conditioned tertiary institutional building in the tropics. Build. Environ. 38: 605-616.

Cole, E.C. and Cook, C.E. (1998). Characterization of infectious aerosols in health care facilities: An aid to effective engineering controls and preventive strategies. Am. J. Infect. Control 26: 453-464.

Daniels, C.C., Rogers, P.D. and Shelton, C.M. (2016). A review of pneumococcal vaccines: Current polysaccharide vaccine recommendations and future protein antigens. $J$. Pediatr. Pharmacol. Ther. 21: 27-35.

Du, P., Du, R., Lu, Z., Ren, W. and Fu, P. (2018). Variation of bacterial and fungal community structures in $\mathrm{PM}_{2.5}$ collected during the 2014 APEC summit periods. Aerosol Air Qual. Res. 18: 444-455.

Fan, H., Li, X., Deng, J., Da, G., Gehin, E. and Yao, M. (2017). Time-dependent size-resolved bacterial and fungal aerosols in Beijing subway. Aerosol Air Qual. Res. 17: 799-809.

Fotedar, R., Shriniwas, U.B. and Verma, A. (1991). Cockroaches (Blattella germanica) as carriers of microorganisms of medical importance in hospitals. Epidemiol. Infect. 107: 181-187.

Green, C.F., Scarpino, P.V. and Gibbs, S.G. (2003). Assessment and modeling of indoor fungal and bacterial bioaerosol concentrations. Aerobiologia 19: 159-169.

Hammamieh, R., Muhie, S., Borschel, R., Gautam, A., Miller, S.A., Chakraborty, N. and Jett, M. (2016). Temporal progression of pneumonic plague in blood of nonhuman primate: A transcriptomic analysis. PLoS One 11: e0151788.

Hargreaves, M., Parappukkaran, S., Morawska, L., Hitchins, J., He, C. and Gilbert, D. (2003). A pilot investigation into associations between indoor airborne fungal and nonbiological particle concentrations in residential houses in Brisbane, Australia. Sci. Total Environ. 312: 89-101.

Hathway, E., Noakes, C., Sleigh, P. and Fletcher, L. (2011). CFD simulation of airborne pathogen transport due to human activities. Build. Environ. 46: 2500-2511.

Heseltine, E. and Rosen, J. (2009). Who Guidelines for Indoor Air Quality: Dampness and Mould. WHO Regional Office Europe.

Hodgson, M.J., Morey, P., Leung, W.Y., Morrow, L., Miller, D., Jarvis, B.B., Robbins, H., Halsey, J.F. and Storey, E. (1998). Building-associated pulmonary disease from exposure to Stachybotrys chartarum and Aspergillus versicolor. J. Occup. Environ. Med. 40: 241-249.

Iyengar, R.S. (2014). The decentralized approach to achieve comfortable indoor environments in tropical climates using low-exergy techniques of integrated design. Doctoral dissertation, ETH Zurich.

Jutel, M., Agache, I., Bonini, S., Burks, A.W., Calderon, M., Canonica, W., Cox, L., Demoly, P., Frew, A.J. and O'hehir, R. (2016). International Consensus on Allergen Immunotherapy II: Mechanisms, standardization, and pharmacoeconomics. J. Allergy Clin. Immunol. 137: 358368.

Kamath, U., Singer, C. and Isenberg, H. (1992). Clinical significance of Staphylococcus warneri bacteremia. J. Clin. Microbiol. 30: 261-264.

Kauffman, H.F. and van der Heide, S. (2003). Exposure, sensitization, and mechanisms of fungus-induced asthma. Curr. Allergy Asthma Rep. 3: 430-437.

Kim, H. and Haberl, J.S. (2012). Field-test of the new ASHRAE/CIBSE/USGBC Performance Measurement Protocols: Intermediate and advanced Level Indoor Environmental Quality protocols. ASHRAE Trans. 118: $58+$.

Kim, K.H., Kabir, E. and Jahan, S.A. (2017). Airborne bioaerosols and their impact on human health. J. Environ. Sci. 67: 23-35

King, M.F., Noakes, C., Sleigh, P. and Camargo-Valero, M. (2013). Bioaerosol deposition in single and two-bed hospital rooms: A numerical and experimental study. Build. Environ. 59: 436-447.

Lai, A.C. and Nazaroff, W.W. (2000). Modeling indoor particle deposition from turbulent flow onto smooth surfaces. J. Aerosol Sci. 31: 463-476.

Lai, A.C. (2002). Particle deposition indoors: A review. Indoor Air 12: 211-214.

Lal, H., Ghosh, B., Srivastava, A. and Srivastava, A. (2017). Identification and characterization of size-segregated bioaerosols at different sites in Delhi. Aerosol Air Qual. Res. 17: 1570-1581.

Liu, S., Wang, H., Su, M., Hwang, G.J., Hong, J. and Jung, J.H. (2017). New metabolites from the sponge-derived fungus Aspergillus sydowii J05B-7F-4. Nat. Prod. Res. 31: 1682-1686.

Lu, Z., Lu, W., Zhang, J. and Sun, D. (2009). Microorganisms and particles in AHU systems: Measurement and analysis. Build. Environ. 44: 694-698.

Luhung, I., Wu, Y., Xu, S., Yamamoto, N., Chang, V.W.C. and Nazaroff, W.W. (2017). DNA accumulation on ventilation system filters in university buildings in Singapore. PLoS One 12: e0186295.

Macher, J.M. (1989). Positive-hole correction of multiplejet impactors for collecting viable microorganisms. Am. Ind. Hyg. Assoc. J. 50: 561-568.

Madsen, A.M., Larsen, S.T., Koponen, I.K., Kling, K.I., Barooni, A., Karottki, D.G., Tendal, K. and Wolkoff, P. (2016). Generation and characterization of indoor fungal aerosols for inhalation studies. Appl. Environ. Microbiol. 82: 2479-2493.

Milton, D.K., Glencross, P.M. and Walters, M.D. (2000). Risk of indoor airborne infection transmission estimated from carbon dioxide concentration. Indoor Air 10: 212221. 
Ministry of Health Singapore (2017). Updated Biological Agents and Toxins List. https://www.moh.gov.sg/docs/li brariesprovider $7 /$ news-updates-documents/amendmentsto-bata-first-schedule-2017.pdf, Last Access: August 2017.

Nazaroff, W.W. (2016). Indoor bioaerosol dynamics. Indoor Air 26: 61-78.

Nazaroff, W.W. and Cass, G.R. (1986). Mathematical modeling of chemically reactive pollutants in indoor air. Environ. Sci. Technol. 20: 924-934.

Pedersen, M.K., Andersen, A.B., Andersen, P.H., Svensson, E., Jensen, S.G. and Lillebaek, T. (2016). Occupational tuberculosis in Denmark through 21 years analysed by nationwide genotyping. PLoS One 11: e0153668.

Scheff, P.A., Paulius, V.K., Curtis, L. and Conroy, L.M. (2000). Indoor air quality in a middle school, Part II: Development of emission factors for particulate matter and bioaerosols. Appl. Occup. Environ. Hyg. 15: 835-842.

Schmidt, M.G., Attaway, H.H., Terzieva, S., Marshall, A., Steed, L.L., Salzberg, D., Hamoodi, H.A., Khan, J.A., Feigley, C.E. and Michels, H.T. (2012). Characterization and control of the microbial community affiliated with copper or aluminum heat exchangers of HVAC systems. Curr. Microbiol. 65: 141-149.

Shahandeh, Z., Shafi, H. and Sadighian, F. (2015). Association of staphylococcus cohnii subspecies urealyticum infection with recurrence of renal staghorn stone. Caspian J. Intern. Med. 6: 40.

Siegel, J. and Carey, V.P. (2001). Fouling of Hvac Fin and Tube Heat Exchangers, Report No. LBNL-47668, Lawrence Berkeley National Laboratory, Berkeley, CA.

Siegel, J.A. (2002). Particulate Fouling of HVAC Heat Exchangers, University of California, Berkeley.

Singapore Standards Council (2016). Singapore Standard SS 554: 2016: Code of Practice for Indoor Air Quality for Air-Conditioned Buildings. Building and Construction Standards Committee, Institution of Engineers, Singapore.

Sutton, S. (2011). Accuracy of plate counts. J. Validation Technol. 17: 42-46.

Tevell, S., Hellmark, B., Nilsdotter-Augustinsson, A. and Söderquist, B. (2017). Staphylococcus capitis isolated from prosthetic joint infections. Eur. J. Clin. Microbiol. Infect. Dis. 36: 115-122.

Thatcher, T.L. and Layton, D.W. (1995). Deposition, resuspension, and penetration of particles within a residence. Atmos. Environ. 29: 1487-1497.

Vesper, S., McKinstry, C., Haugland, R., Neas, L., Hudgens, E., Heidenfelder, B. and Gallagher, J. (2008). Higher
Environmental Relative Moldiness Index (ERMIsm) values measured in Detroit homes of severely asthmatic children. Sci. Total Environ. 394: 192-196.

Whyte, W. and Derks, M. (2015). Airborne particle deposition in cleanrooms: Deposition mechanisms. Clean Air Containment Rev. 24: 4-9.

Wiedinmyer, C., Guenther, A., Harley, P., Hewitt, N., Geron, C., Artaxo, P., Steinbrecher, R. and Rasmussen, R. (2004). Global Organic Emissions from Vegetation. In Emissions of Atmospheric Trace Compounds, Springer, pp. $115-170$.

Wiedinmyer, C., Bowers, R.M., Fierer, N., Horanyi, E., Hannigan, M., Hallar, A.G., McCubbin, I. and Baustian, K. (2009). The contribution of biological particles to observed particulate organic carbon at a remote high altitude site. Atmos. Environ. 43: 4278-4282.

Wu, Y., Chen, A., Luhung, I., Gall, E.T., Cao, Q., Chang, V.W.C. and Nazaroff, W.W. (2016). Bioaerosol deposition on an air-conditioning cooling coil. Atmos. Environ. 144: 257-265.

Xu, L., Zhou, L., Zhao, J., Li, J., Li, X. and Wang, J. (2008). Fungal Endophytes from dioscorea zingiberensis rhizomes and their antibacterial activity. Lett. Appl. Microbiol. 46: 68-72.

Yamada, A., Kasahara, K., Ogawa, Y., Samejima, K., Eriguchi, M., Yano, H., Mikasa, K. and Tsuruya, K. (2019). Peritonitis due to Moraxella osloensis: A case report and literature review. J. Infect. Chemother. 25: 1050-1052.

You, S. and Wan, M.P. (2014). Particle concentration dynamics in the ventilation duct after an artificial release: For countering potential bioterrorist attack. J. Hazard. Mater. 267: 183-193.

Zhao, B. and Wu, J. (2006). Modeling particle deposition from fully developed turbulent flow in ventilation duct. Atmos. Environ. 40: 457-466.

Zhao, B. and Wu, J. (2009). Particulate pollution in ventilated space: Analysis of influencing factors. $J$. Hazard. Mater. 163: 454-462.

Zhou, B., Zhao, B. and Tan, Z. (2011). How particle resuspension from inner surfaces of ventilation ducts affects indoor air quality-A modeling analysis. Aerosol Sci. Technol. 45: 996-1009.

Received for review, May 15, 2019 Revised, October 18, 2019 Accepted, February 25, 2020 